\title{
Synthesis, Characterization and Dielectric Properties of $\mathrm{K}_{1-\mathrm{x}} \mathrm{Na}_{\mathbf{x}} \mathrm{NbO}_{3}$
}

\author{
S C Bhatt ${ }^{*}$, Manish Uniyal
}

Department of Physics, H.N.B Garhwal University, Srinagar (Garhwal), 246174, Uttarakhand, India

\begin{abstract}
The samples of $\mathrm{K}_{1-\mathrm{x}} \mathrm{Na}_{\mathrm{x}} \mathrm{NbO}_{3}(\mathrm{X}=0.4,0.2,0)$ ceramics (PSN) have been prepared by the conventional solidstate reaction method and sintering process. The prepared samples have been characterized by XRD. All the prepared samples show orthorhombic structure at room temperature. Dielectric and Electrical properties of PSN system have been investigated in the temperature range $45^{\circ} \mathrm{C}-245^{\circ} \mathrm{C}$, and at $1 \mathrm{MHz}$ frequency. It is observed that dielectric constant, loss tangent and electrical conductivity increases with increasing temperature. Near the transition temperature dielectric constant, loss tangent and electrical conductivity of these samples show anomalous behaviour with temperature.
\end{abstract}

Keywords Transition Temperature, Dielectric Constant, Loss Tangent, Electrical Conductivity

\section{Introduction}

$\mathrm{ABO}_{3}$ Perovskite type materials are of considerable technological importance, particularly with respect to their physical properties such as ferro, pyro-and piezo-electricity, dielectric susceptibility, linear \& non linear electro-optic properties etc. The change in physical properties is particularly large when the external conditions, such as temperature, pressure, electric-field, composition etc. are altered. Such effects occur in connection with the simultaneous presence of phase transition in the system, where the atomic structure of the perovskite changes either discontinuously or continuously into another form. The dielectric properties of $\mathrm{ABO}_{3}$ perovskite structure $\mathrm{K}_{1-\mathrm{x}} \mathrm{Na}_{\mathrm{x}}$ $\mathrm{NbO}_{3}$ for some of the compositions has been extensively studied at high temperature[1] and it shows a number of ferroelectric phases with high spontaneous polarization. The solid solution of ferroelectric $\mathrm{KNbO} 3$ and antiferroelectric $\mathrm{NaNbO} 3$ exhibits good piezoelectric properties[2,3]. Potassium Sodium Niobate ceramic $\left(\mathrm{K}_{1-\mathrm{x}} \mathrm{Na}_{\mathrm{x}} \mathrm{NbO}_{3}\right)$ with perovskite structures are widely used for transducer applications with broad ranges of technologically important dielectric, piezoelectric, ferroelectric and electro-optic properties. The structure of PSN system at room temperature is basically of the orthorhombic type. $\mathrm{K}_{1 \text { - }}$ ${ }_{x} \mathrm{Na}_{\mathrm{x}} \mathrm{NbO}_{3}(\mathrm{x}=0)$ is a particularly promising ferroelectric with its combination of relatively low dielectric constant $(\varepsilon 1=155, \varepsilon 2=44$, and $\varepsilon 3=980)$ with extremely high electro-optic coefficients $\left(\mathrm{r}_{42}=380 \mathrm{pm} / \mathrm{V}, \mathrm{r}_{33}=64 \mathrm{pm} / \mathrm{V}\right)$. This

* Corresponding author: scbhattin@yahoo.com,(S.C.Bhatt)

Published online at http://journal.sapub.org/ijmc

Copyright (C) 2012 Scientific \& Academic Publishing. All Rights Reserved makes $\mathrm{KNbO}_{3}$ vary attractive for opto-electronic devices, including high-speed electro-optic switches, modulators, and frequency doublers[4-7]. Dielectric measurements on this material were first reported by Matthias and Remeika [8] and then by Shirane et. al.[9] and observed well defined ferroelectric hystersis loops from room temperature to $400^{\circ} \mathrm{C}$, for compositions form about 10 to $100 \%$ (mol) of $\mathrm{K}$ in $\mathrm{K}_{1-\mathrm{x}} \mathrm{Na}_{\mathrm{x}} \mathrm{NbO}_{3}$. Dielectric properties were reported by Narayan Murty et. al. [10]. Cross [11] has predicted, theoretically, the phase-diagram of $\mathrm{KNbO}_{3}-\mathrm{NaNbO}_{3}$ mixture from phenomenological arguments. The mixing of $\mathrm{NaNbO}_{3}$ in $\mathrm{KNbO}_{3}$ ceramics play an important role on the ferroelectric Curie temperature, dielectric constant, grain size as well as the planer mechanical coupling coefficient $\left(k_{\mathrm{p}}\right)$ value [12-13], because $\mathrm{NaNbO}_{3}$ is anti-ferroelectric at room temperature, when mixed with small amount of $\mathrm{KNbO}_{3}$, becomes ferroelectric, which creates interest in the present investigation to investigate this system with a varying composition and temperature range. In this paper, we report the results of investigation on dielectric constant, tangent loss and electrical conductivity of the ceramic system $\mathrm{K}_{1-\mathrm{x}} \mathrm{Na}_{\mathrm{x}} \mathrm{NbO}_{3}(\mathrm{x}=0.4,0.2 \& 0)$ prepared by solid state reaction method and sintering process, in the temperature range $45^{\circ} \mathrm{C}-245^{\circ} \mathrm{C}$, and at $1 \mathrm{M} \mathrm{Hz}$ frequency.

\section{Preparation}

The starting material was dried at $200^{\circ} \mathrm{C}$ for one hour to remove absorbed moisture. Different compositions of $\mathrm{K}_{1}$ ${ }_{x} \mathrm{Na}_{\mathrm{x}} \mathrm{NbO}_{3}$ for $(\mathrm{x}=0.4,0.2 \& 0)$ were prepared by weighing the sodium carbonate, potassium carbonate and niobium penta-oxide (starting materials) in proper stoichiometric proportions. The mixture was calcined in the platinum crucible, in air, at $950^{\circ} \mathrm{C}$ for $2 \mathrm{~h}$, for carbonate removal. 
After cooling, in dry air, the calcined mixtures were weighed to ensure complete carbonate removal.

The pre-sintered mixture was ground and pressed into pellets of $10 \mathrm{~mm}$ diameter. All the pellets were placed on a platinum crucible and sintered, in air, at $1050^{\circ} \mathrm{C}$ for $26 \mathrm{~h}$. The sintered pellets were electroded using air-drying silver paste for dielectric measurements.

\section{Characterization}

$\mathrm{X}$-ray powder studies were performed at room temperature with a SEIFERT 3000P X-ray diffractometer using filtered $\mathrm{Cu} K \alpha_{1}$ radiation of $1.540598^{\circ} \mathrm{A}$ wavelength, in which, $\mathrm{Ni}$, is used as filter. The instrument is well calibrated with silicon standard samples and the lines obtained are matching with the standard lines. At room temperature all PSN ceramic samples exhibit the orthorhombic symmetry. The sub cell parameters were obtained using the auto-X computer software and were compatible with those obtained earlier for ceramics $[10,12$ 17]. The results are summarized in following table-

Table A. Lattice parameters of $\mathrm{K}_{1-\mathrm{X}} \mathrm{Na}_{\mathrm{X}} \mathrm{NbO}_{3}$ for different compositions at room temperature

\begin{tabular}{|c|c|c|c|}
\hline \multirow{2}{*}{ composition } & \multicolumn{3}{|c|}{ Lattice parameters $^{\circ} \mathrm{A}$} \\
\cline { 2 - 4 } & $\mathrm{a}$ & $\mathrm{b}$ & $\mathrm{c}$ \\
\hline $\mathrm{KNbO3}$ & 4.027 & 4.057 & 3.958 \\
\hline $\mathrm{K}_{0.8} \mathrm{Na}_{0.2} \mathrm{NbO}_{3}$ & 4.002 & 4.040 & 3.946 \\
\hline $\mathrm{K}_{0.6} \mathrm{Na}_{0.4} \mathrm{NbO}_{3}$ & 3.998 & 4.011 & 3.919 \\
\hline
\end{tabular}

\section{Measurements}

The variation of dielectric constant, loss tangent and electrical conductivity at $1 \mathrm{MHz}$ frequency, in the temperature range $45^{\circ} \mathrm{C}-245^{\circ} \mathrm{C}$ have been studied and plotted in Fig. 1, 2 \& 3 respectively. These measurements were performed on HP Impedance Analyzer and FLUKE RCL meter, PM 6306.

\section{Result and Discussions}

We have measured dielectric constant, loss tangent of $\mathrm{K}_{0.6} \mathrm{Na}_{0.4} \mathrm{NbO}_{3}, \mathrm{~K}_{0.8} \mathrm{Na}_{0.2} \mathrm{NbO}_{3}$ and $\mathrm{KNbO}_{3}$ ceramic pellets using HP Impedance Analyzer and Fluke RCL meter PM 6304 , at the temperatures from $45^{\circ} \mathrm{C}$ to $245^{\circ} \mathrm{C}$. The temperature dependence of dielectric constant, loss tangent and conductivity at $1 \mathrm{MHz}$ have been shown in Figs 1, 2 \& 3, and tables-1,2 \& 3, respectively.

From these figures (Fig.1-3) and tables (Tables 1-3), it is observed that the mixed system of $\mathrm{K}_{1-\mathrm{x}} \mathrm{Na}_{\mathrm{x}} \mathrm{NbO}_{3}$ has a transition from orthorhombic to tetragonal at about $220^{\circ} \mathrm{C}$. It is $225^{\circ} \mathrm{C}$ for $\mathrm{KNbO}_{3}, 215^{\circ} \mathrm{C}$ for $\mathrm{K}_{0.8} \mathrm{Na}_{0.2} \mathrm{NbO}_{3}$ and $205^{\circ} \mathrm{C}$ for $\mathrm{K}_{0.6} \mathrm{Na}_{0.4} \mathrm{NbO}_{3}$, which shows that transition temperature from orthorhombic to tetragonal shifts towards lower temperature as we increases the quantity of anti- ferroelctric material sodium niobate in the mixed system of $\mathrm{K}_{1}$. ${ }_{\mathrm{X}} \mathrm{Na}_{\mathrm{X}} \mathrm{NbO}_{3}$, which is in agreement with previous observations[1,18]. Lattice parameters of $\mathrm{K}_{1-\mathrm{X}} \mathrm{Na}_{\mathrm{X}} \mathrm{NbO}_{3}$ for different compositions at room temperature have been shown in table-A, which shows a decrease in lattice parameters as we add antiferroelectric material $\mathrm{NaNbO}_{3}$ in mixed system of $\mathrm{K}_{1-\mathrm{x}} \mathrm{Na}_{\mathrm{x}} \mathrm{NbO}_{3}$ ceramic.

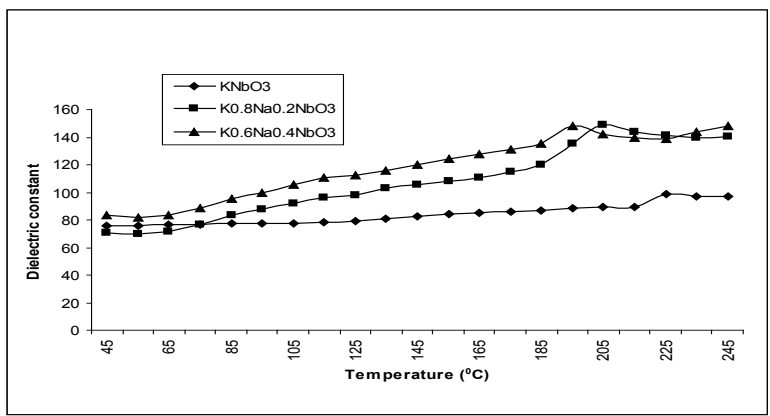

Figture 1. Variation of dielectric constant with temperature for $\mathrm{K}_{1 \text { - }}$ ${ }_{x} \mathrm{Na}_{\mathrm{x}} \mathrm{NbO}_{3}$ at $1 \mathrm{MHz}$

Table 1. Variation of dielectric constant with temperature for $\mathrm{K}_{1-\mathrm{x}} \mathrm{Na}_{\mathrm{x}} \mathrm{NbO}_{3}$, at $1 \mathrm{MHz}$ frequency

\begin{tabular}{|c|c|c|c|}
\hline Temperature ${ }^{0} \mathrm{C}$ & $\mathrm{KNbO}_{3}$ & $\mathrm{~K}_{0.8} \mathrm{Na}_{0.2} \mathrm{NbO}_{3}$ & $\mathrm{~K}_{0.6} \mathrm{Na}_{0.4} \mathrm{NbO}_{3}$ \\
\hline 45 & 76.17 & 70.57 & 83.680 \\
\hline 55 & 76.17 & 069.88 & 81.910 \\
\hline 65 & 76.52 & 071.41 & 83.270 \\
\hline 75 & 76.88 & 076.81 & 88.670 \\
\hline 85 & 77.22 & 083.57 & 95.320 \\
\hline 95 & 77.39 & 087.35 & 99.690 \\
\hline 105 & 77.71 & 092.11 & 105.20 \\
\hline 115 & 78.58 & 096.23 & 110.40 \\
\hline 125 & 79.18 & 097.81 & 112.06 \\
\hline 135 & 81.10 & 102.61 & 115.49 \\
\hline 145 & 82.74 & 105.50 & 120.27 \\
\hline 155 & 83.95 & 107.75 & 124.01 \\
\hline 165 & 85.14 & 110.37 & 127.45 \\
\hline 175 & 86.13 & 115.11 & 130.77 \\
\hline 185 & 87.35 & 120.25 & 134.93 \\
\hline 195 & 88.54 & 135.34 & 148.03 \\
\hline 205 & 89.39 & 149.11 & 141.86 \\
\hline 215 & 89.73 & 144.07 & 139.39 \\
\hline 225 & 98.58 & 141.05 & 138.67 \\
\hline 235 & 97.17 & 139.48 & 143.46 \\
\hline 245 & 96.60 & 140.48 & 147.98 \\
\hline
\end{tabular}

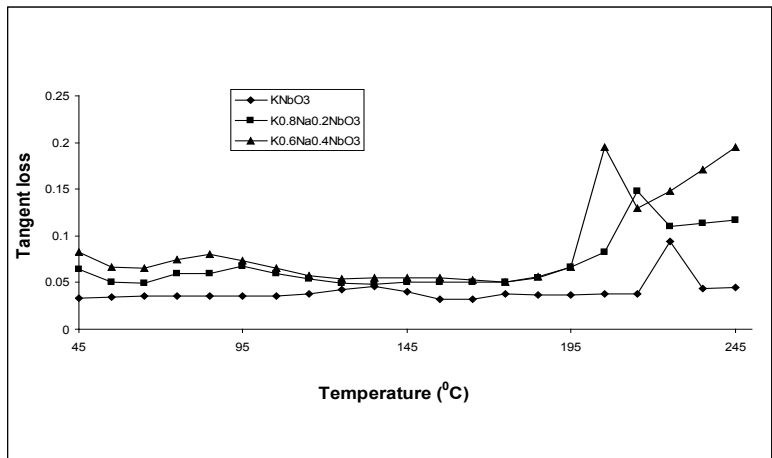

Figture 2. Variation of tangent loss with temperature for $\mathrm{K}_{1-\mathrm{x}} \mathrm{Na}_{\mathrm{x}} \mathrm{NbO}_{3}$ system at $1 \mathrm{MHz}$ 
Table 2. Variation of loss tangentfor $\mathrm{K}_{1-\mathrm{x}} \mathrm{Na}_{\mathrm{x}} \mathrm{NbO}_{3}$, with temperature, at 1 MHz frequency

\begin{tabular}{|c|c|c|c|}
\hline Temperature ${ }^{0} \mathrm{C}$ & $\mathrm{KNbO}_{3}$ & $\mathrm{~K}_{0.8} \mathrm{Na}_{0.2} \mathrm{NbO}_{3}$ & $\mathrm{~K}_{0.6} \mathrm{Na}_{0.4} \mathrm{NbO}_{3}$ \\
\hline 45 & 0.033 & 0.064 & 0.082 \\
\hline 55 & 0.034 & 0.051 & 0.066 \\
\hline 65 & 0.035 & 0.049 & 0.065 \\
\hline 75 & 0.035 & 0.060 & 0.074 \\
\hline 85 & 0.035 & 0.068 & 0.080 \\
\hline 95 & 0.035 & 0.060 & 0.073 \\
\hline 105 & 0.036 & 0.054 & 0.065 \\
\hline 115 & 0.038 & 0.049 & 0.057 \\
\hline 125 & 0.043 & 0.047 & 0.054 \\
\hline 135 & 0.046 & 0.048 & 0.055 \\
\hline 145 & 0.040 & 0.050 & 0.055 \\
\hline 155 & 0.032 & 0.050 & 0.055 \\
\hline 165 & 0.032 & 0.050 & 0.053 \\
\hline 175 & 0.038 & 0.050 & 0.051 \\
\hline 185 & 0.037 & 0.055 & 0.056 \\
\hline 195 & 0.037 & 0.066 & 0.067 \\
\hline 205 & 0.038 & 0.082 & 0.086 \\
\hline 215 & 0.038 & 0.102 & 0.130 \\
\hline 225 & 0.040 & 0.110 & 0.148 \\
\hline 235 & 0.044 & 0.114 & 0.171 \\
\hline 245 & 0.045 & 0.117 & 0.195 \\
\hline
\end{tabular}

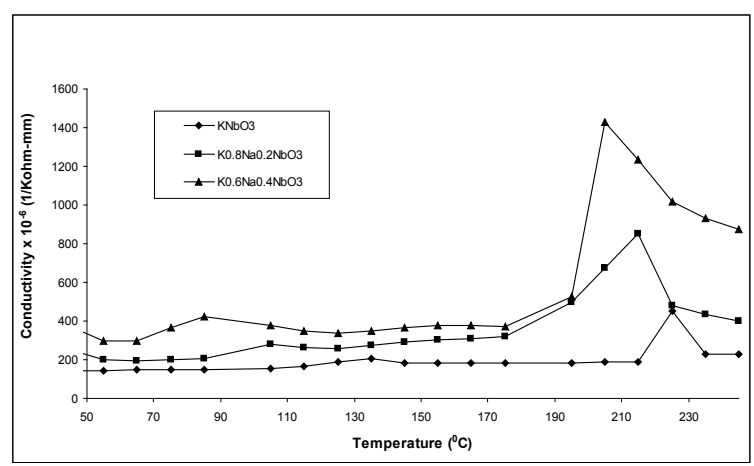

Figture 3. Variation of electrical conductivity with temperature for $\mathrm{K}_{1 \text { - }}$ ${ }_{\mathrm{x}} \mathrm{Na}_{\mathrm{x}} \mathrm{NbO}_{3}$ system at $1 \mathrm{MHz}$

Table 4. Variation of electrical conductivity of $\mathrm{K}_{1-\mathrm{x}} \mathrm{Na}_{\mathrm{x}} \mathrm{NbO}_{3}$ with temperature, at $1 \mathrm{MHz}$ frequency

\begin{tabular}{|c|c|c|c|}
\hline $\begin{array}{c}\text { Temperature } \\
{ }^{0} \mathrm{C}\end{array}$ & $\begin{array}{c}\mathrm{KNbO}_{3} \\
\left(\mathrm{X} 10^{-06}\right)\end{array}$ & $\begin{array}{c}\mathrm{K}_{0.8} \mathrm{Na}_{0.2} \mathrm{NbO}_{3} \\
\left({\left.\mathrm{X} 10^{-6}\right)}^{3}\right.\end{array}$ & $\begin{array}{c}\mathrm{K}_{0.6}\left(\mathrm{Na}_{0.4} \mathrm{NbO}_{3}\right. \\
\left(\mathrm{X} 10^{-6}\right)\end{array}$ \\
\hline 45 & 141 & 250 & 372 \\
\hline 55 & 145 & 198 & 299 \\
\hline 65 & 147 & 195 & 298 \\
\hline 75 & 150 & 255 & 364 \\
\hline 85 & 151 & 265 & 422 \\
\hline 95 & 152 & 290 & 405 \\
\hline 105 & 155 & 278 & 380 \\
\hline 115 & 164 & 264 & 349 \\
\hline 125 & 188 & 257 & 340 \\
\hline 135 & 205 & 276 & 350 \\
\hline 145 & 184 & 290 & 366 \\
\hline 155 & 182 & 301 & 380 \\
\hline 165 & 181 & 310 & 378 \\
\hline 175 & 181 & 322 & 369 \\
\hline 185 & 181 & 365 & 417 \\
\hline 195 & 183 & 498 & 528 \\
\hline 205 & 187 & 677 & 707 \\
\hline
\end{tabular}

\section{Conclusions}

Our results shows that the mixing of $\mathrm{Na}$ is effective in promoting the densification of the ceramics and can be well sintered and exhibit a dense, pure perovskite structure and this is attributed to the fact of the presence of oxygen vacancies. For most KNN-based solid solutions, the piezoelectric properties are enhanced but with a reduced $T_{c}$ [19]. Therefore as $20 \%$ mixing of $\mathrm{Na}$, transition temperature is $215^{\circ} \mathrm{C}$ whereas $40 \%$ mixing of $\mathrm{Na}$, transition temperature reduces to $205^{\circ} \mathrm{C}$, which shows that transition temperature from orthorhombic to tetragonal shifts towards lower temperature as we increase the quantity of anti ferroelectric material $\mathrm{NaNbO}_{3}$ in the mixed system, $\mathrm{K}_{1 \text { - }}$ ${ }_{\mathrm{X}} \mathrm{Na}_{\mathrm{X}} \mathrm{NbO}_{3}$.

\section{ACKNOWLEDGEMENTS}

The authors are thankful to IIT Delhi, NPL Delhi \& IIT Roorkee for library facilities and Material Science Research Centre. IIT Madras, for providing laboratory facilities for sample preparation and characterization.

\section{REFERENCES}

[1] Singh K, Lingwal V, Bhatt S C, Panwar N S \& Semwal B S,2001, Material Research Bulletin, 36,365-2374

[2] Ahn C W, Song H C et.al.,2005, Japanese Journal of Applied Physics, 44,1361-1364

[3] Ahn C W, Choi C H ,2008, Journal of Material Science, 43,6784-6797

[4] Holman R L, Althouse Johnson L M \& Skinner D P,1987, Opt Eng 26, 134

[5] Nystrom M J, Wessels BW, Chen J \& Marks T J,1996, Appl Phys Lett 68,761

[6] Hoerman B H, Jichlos B M, Nystrom M J \& Wessels B W,1999, Appl Phys Lett 75, 2707

[7] Maeder M D, Damjanovic D, Setter N,2004, Journal of electroceramics 13,385-392

[8] Matthias B T, Remeika J P,1951, Phys Rev 82, 727

[9] Shirane G, Newniham R \& Pepinsky R,1954, Phys Rev 96(3), 581

[10] Narayana Murty S, Ramana Murty K V, Umakanthan K \& Bhanumati A,1990, Ferroelectrics, 102, 243

[11] Cross L E, 1958, Nature, 181, 178

[12] Lin D , Kwok K W and Chan H L W,2007, Journal of Applied Physics 102, 074113

[13] Chu S Y, Water W, Juang Y D \& Liaw J T,2003, Ferroelectrics, 287, 23-33

[14] Natl. Bur Stand, (U.S.) Monogr.1980, 25, 17, 62

[15] Katz L \& Megaw H D,1967, Acta Crystallogr, 22, 639 
[16] Wood E A,1951, Acta Crystallogr. 4, 353

[17] Hearthing G H,1967, J Amer Cerm Soc, 50,330
[18] Shirane G, Newnham R \& Pepinsky R, 1954, Phys Rev 96,581

[19] Sun X, Chen J et.al,2009, J.Am.Ceram. Soc., 92[1] 130-132 